\title{
A Case Report and Literature Review: \\ Primordial Dwarfism: A Case Series From North East of Iran and Literature Review
}

\author{
Rahim Vakili, ${ }^{1,2}$ (D) Somayyeh Hashemian ${ }^{1^{*}}$ (D)
}

1. Department of Pediatrics, Faculty of Medicine, Imam Reza Hospital, Mashhad University of Medical Sciences, Mashhad, Iran

2. Medical Genetic Research Center, Mashhad University of Medical Sciences, Mashhad, Iran.

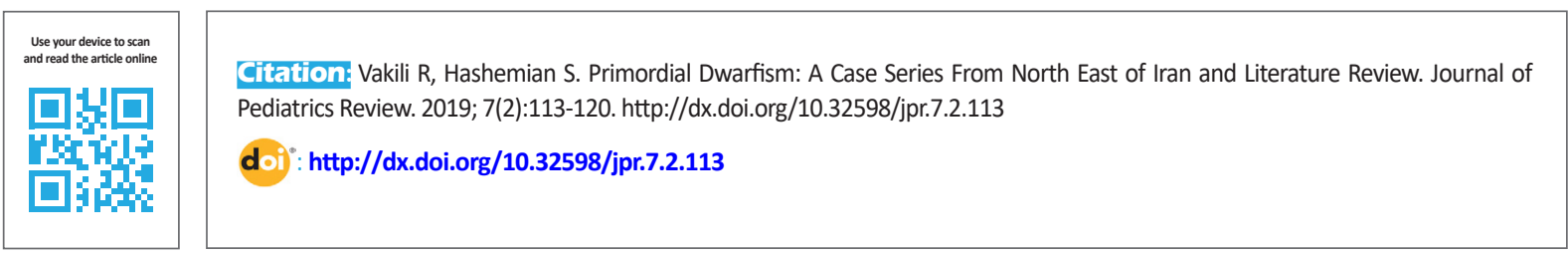

\section{(c) (1) (s)}

Funding: See Page 119

Article info:

Received: 15 February 2018

First Revision: 10 March 2018

Accepted: 30 May 2018

Published: 01 April 2019

Keywords:

Growth retardation, Microcephaly, RussellSilver syndrome, Clinical findings

\begin{abstract}
A B S T R A C T
Introduction: Primordial dwarfism is a rare class of genetic disorders, characterized by intrauterine growth retardation, short stature at birth and growth deficiency that persist throughout life. This disorder is caused by various mechanisms such as chromosomal abnormalities, molecular changes and mutation of genes that result in developmental defects, facial dysmorphism and skeletal abnormalities in fetus. Primordial dwarfism includes 5 specific subtypes that their descriptions vary from one type to another. This study aimed to report 7 cases of primordial dwarfism as the first case series study and literature review of this disorder in Iran.

Case Presentations: This study presented primordial dwarfism patients and summarized clinical findings of 7 cases who referred to Pediatric endocrine wards in Imam Reza Hospital, from June 2016 to September 2017. The cases suffered from severe growth retardation and clinical features of this disorder that were not explained by other disorders. We also conducted a literature review about primordial dwarfism on Google Scholar, Medline, and PubMed to compare our results with other reports. Seven patients ( 5 females and 2 males) aged between 18 months and 12 years were identified, during the study. The most prevalent referring symptoms were growth retardation, presenting in all cases. Other clinical signs and symptoms included intrauterine growth retardation, low birth weight, specific clinical features such as microcephaly, narrow face, high pitch voice, prominent nose, etc. Biochemical and imaging studies were performed to rule out other diseases that can cause growth retardation. The diagnosis of primordial dwarfism was made based o clinical presentation.
\end{abstract}

Conclusions: This review will provide an overview of the clinical aspects and different subtypes of primordial dwarfism disorder and draw the attention of clinicians for diagnose and further evaluations of this disorder.

\section{* Corresponding Author:}




\section{Introduction}

rimordial Dwarfism (PD) is a group of disorders with significant prenatal and postnatal growth retardation and various clinical abnormalities that differ from one type to another (1). PD is characterized by intrauterine growth retardation, low birth weight, and Small (bones and body organs) for Gestational Age (SGA). Female and male patients are equally affected and look smaller in size (weight and height) compared to normal individuals (2). The main specific feature of PD that differentiates it from other forms of dwarfism is reduced head size in proportion to body, called "microcephalic primordial dwarfism." There is only 1 subtype of PD with normal head size, called Russell-Silver Syndrome (RSS). Clinical findings vary from one subtype to another. Molecular, genetic and chromosomal changes can contribute in development of PD (3).

PD is a rare heterogeneous condition and diagnostic category including specific features in 5 major subtypes. The main feature in all subtypes is prenatal and postnatal growth retardation. Patients are very small for their age and sex. They are diagnosed with Intrauterine Growth Retardation (IUGR) and often have premature delivery and low birth weight (SGA). Growth delay continues after birth (1).

Five subtypes in PD include Seckel syndrome, Majewski Osteodysplastic Primordial Dwarfism (MOPD type I/ III), MOPD type II, Meier-Gorlin syndrome and RussellSilver Syndrome (1). Russell-Silver syndrome is a specific group of patients with normal head size; other types have microcephaly (3). Seckel Syndrome (SS) is a rare autosomal recessive disorder (4) and first defined by Seckel in 1960. He described 2 case studies by himself and 13 cases documented in the literature, over a 200year period, characterized by severe microcephaly, large beaked nose, and mild to moderate mental retardation and called it bird-headed dwarfism (5).

In 1982, Majewski et al. introduced the term osteodysplastic primordial dwarfism through literature review. They classified it in 3 categories according to growth and mental retardation, bony anomalies and specific radiologic findings (6). Russell-Silver syndrome was first reported by Russell and Silver in the 1950's and 1960's. The characteristic features of Russell-Silver syndrome are low birth weight, short stature, body asymmetry and normal head size (1). Meier-Gorlin syndrome (ear-patella-short stature syndrome) is another type of PD that is an autosomal recessive dis- order. Meier et al. first described a case with micrognathia, microtia, absent patellae and cryptorchidism in 1959 (7). Further clinical diagnostic criteria of these subtypes are presented in Table 1.

We presented 7 patients with different clinical presentations of this disorder. All cases had growth retardation from birth and other clinical features that helped us to diagnose the disorder described below. The current study aimed to present this disorder in Iran with its different types for the first time. Genetic samples were not included in this study due to limitations in genetic assays and the expenses of that, in our country. We present these cases of primordial dwarfism and their clinical features as the first time for clinicians and other health care groups.

\section{Case Presentation}

\subsection{Case 1}

An 18-month-old girl was the second born child of non-consanguineous, healthy parents. She was born at 40 weeks of gestation. Pregnancy was complicated by Intrauterine Growth Retardation (IUGR). Birth weight was $1940 \mathrm{~g}$, height was $42 \mathrm{~cm}$ and head circumference was $31 \mathrm{~cm}$, all below the third percentile. Physical examination revealed dysmorphic features, microcephaly, narrow face, receding mandible, pointed nose, dental alterations, microphthalmia (Figure 1a). Other findings were developmental delay in speech and motor skills, as well as strabismus and cataract in ophthalmologic tests. Her older sister had normal physical appearance and mental growth. A diagnosis of Seckel syndrome was made based on these clinical findings.

\subsection{Case 2}

A 5-year-old girl who was the first born child of nonconsanguineous parents who was born at preterm with gestational age of 35 weeks and IUGR delivery. Her birth weight was $870 \mathrm{~g}$, her head circumference was $25 \mathrm{~cm}$ and birth height was $44 \mathrm{~cm}$, all under the third percentile. Her latest weight was $10 \mathrm{~kg}$ (-6.2 SDS [Standard Deviation Score]), with head circumference of $36 \mathrm{~cm}$ and height of $92 \mathrm{~cm}$ (-3.6 SDS). According to the clinical findings, she had severe growth retardation, microcephaly, narrow face, receding mandible, large eyes, dental anomalies and odonthia, bilateral sensory neural hearing loss, flexion contracture of hand finger and mild mental retardation. She was diagnosed with Seckel syndrome (Figure 1b). 
Table 1. Subtypes of primordial dwarfism and their corresponding clinical features

\begin{tabular}{|c|c|}
\hline Primordial Dwarfism Subtypes & Clinical Features \\
\hline Seckel Syndrome & $\begin{array}{l}\text { Severe microcephaly, narrow face, large beaked nose, receding mandible, micrognathia, low-set } \\
\text { ears, dental anomalies, clinodactyly }\end{array}$ \\
\hline MOPD type I/III & Microcephaly, bone dysplasia, dry skin, thinning of scalp hair and eyebrows, bone anomalies \\
\hline MOPD type II & $\begin{array}{l}\text { Microcephaly, prominent nose and eyes and narrow face, microdontia or missing teeth, skeletal } \\
\text { anomalies, abnormal pigmentary changes, squeaky voice }\end{array}$ \\
\hline Russell-Silver syndrome & $\begin{array}{l}\text { Small triangular face, body asymmetry, micrognathia, normal head size, prominent forehead } \\
\text { (pseudo microcephaly), and dental anomalies }\end{array}$ \\
\hline Meier-Gorlin syndrome & $\begin{array}{c}\text { Microcephaly, bilateral small ears, hearing loss, absent or hypoplastic patellae, cryptorchidism, } \\
\text { hypogonadism }\end{array}$ \\
\hline
\end{tabular}

\subsection{Case 3}

An 8-year-old girl, the first born child of consanguineous parents (first cousin parents) who had IUGR at birth (birth weight $1900 \mathrm{~g}$ ), and microcephaly. Growth delay continued after birth. Physical examination revealed a narrow and long midface, high-pitched voice, prominent nose, large eyes, thick eyebrows and small ears. There was feeding problem in infancy. She had the signs of premature thelarche and pubarche at the age of 7 years and had mild mental retardation. She could not walk until the age of 2.5 years. Skeletal imaging showed permanent fusion of 2 wrist bones (Figure $1 \mathrm{c}$ and Figure 2a). She was diagnosed with MOPD II syndrome based on the clinical findings.

\subsection{Case 4}

An 8-year-old girl was referred to our department with severe growth retardation and microcephaly. She weighed $13 \mathrm{~kg}$ (-5.99 SDS). Her height was $92 \mathrm{~cm}$ (-7.2 SDS) and her head circumference was $43 \mathrm{~cm}$. Birth history revealed that she was born at preterm ( 28 weeks). She was the second child of healthy parents (first cousin parents). Her birth weight was $900 \mathrm{~g}$, her length was $30 \mathrm{~cm}$, and head circumference was $20 \mathrm{~cm}$. Pregnancy was complicated with bleeding, fetal decelerations, and premature delivery. A clinical examination revealed diagnostic features of PD in MOPD subgroup such as microcephaly, prominent nose and eyes, hair thinning of scalp hair and eyebrows, microdontia and missing teeth or poor tooth roots.

She was suffering from abnormality in ophthalmologic examination, high-pitched nasal voice, mild mental retardation and poor sleep patterns. She had some skeletal abnormalities such as radial deviation of the fourth and fifth hand fingers, and abnormal development of the hip and dysplasia. She had limping that made her undergo surgery and $\mathrm{X}$-rays revealed avascular necrosis of right femoral head (Figure 1e, Figure 1f and Figure $2 b$ ).
Puberty signs occurred early at the age of 7. Lab tests detected recently developed hematologic abnormalities in her (anemia and thrombocytosis). These findings helped us to diagnose MOPD II based on clinical features of such patients in other reports.

\subsection{Case 5}

A 12-year-old girl, second born child of consanguineous healthy parents (first cousin parents). Her height was $110 \mathrm{~cm}$ (-5.4 SDS), her weight was $16 \mathrm{~kg}$ (-7 SDS) and her occipital frontal circumferences was $44 \mathrm{~cm}$. she had IUGR at birth with birth weight of $1680 \mathrm{~g}$, birth length of $42 \mathrm{~cm}$ and birth head circumference of $27 \mathrm{~cm}$. She exhibited microcephaly, thin hair, widely spaced primary teeth, microdontia, prominent nose and eyes, ophthalmologic disorders, delayed mental development, truncal obesity and precocious puberty (Figure $1 \mathrm{~g}$ and Figure $1 \mathrm{~h}$ ). On the basis of these findings, she was diagnosed with MOPD II.

\subsection{Case 6}

An 18-month-old boy, the second born child of nonrelative healthy parents, was IUGR at birth with birth weight of $1580 \mathrm{~g}$, height of $41 \mathrm{~cm}$, and head circumference of $35 \mathrm{~cm}$. His growth delay continued after birth; however, head circumference was below the normal range. His latest weight was $5500 \mathrm{~g}(-8 \mathrm{SDS})$, his height was $68 \mathrm{~cm}$ (-3.9 SDS), and his circumference was $46 \mathrm{~cm}$. Clinical findings revealed a large head compared to rest of the body (pseudo macrocephaly), triangular small face, small jaw, thin upper lip, prominent forehead, low-set ears, bilateral mild hearing loss. X-ray imaging detected lower limb asymmetry and diastasis symphysis pubis (Figure 1d and Figure 2c). She also suffered from lack of appetite, developmental delay in motor skills and delayed bone age ( 9 months). Furthermore, he had inguinal hernia in infancy. These clinical features and normal head size can be signs of Russell-Silver syndrome. 


\subsection{Case 7}

A 3.5-year-old boy, the first child of healthy parents, was born at 29 weeks of pregnancy. His birth weight was $680 \mathrm{~g}$, height was $33 \mathrm{~cm}$ and head circumference was $25 \mathrm{~cm}$. Growth was delayed after birth, except for head size. His weight was $10 \mathrm{~kg}$ (-4.4 SDS) and height $80 \mathrm{~cm}$ (-5.SDS) in 3.5 years old. Other clinical features included triangular face, small chin, bossed forehead, low-set ears and thin upper lip. He suffered from hypothyroidism and bilateral renal stones that was under medication. These clinical appearances helped us to diagnose him with Russell-Silver syndrome.

We reviewed 7 cases with clinical features of growth insufficiency including prenatal and postnatal growth delay and suspicious signs of primordial dwarfism. The current investigation was the first case series of PD cases in Iran. Therefore, we conducted a literature review on primordial dwarfism through Google Scholar, Medline, and PubMed data bases, to compare our results with previously reported cases. PD is a rare disorder with a spectrum of clinical conditions. Therefore, we selected articles that could help us explain the clinical symptoms and sings of PD.

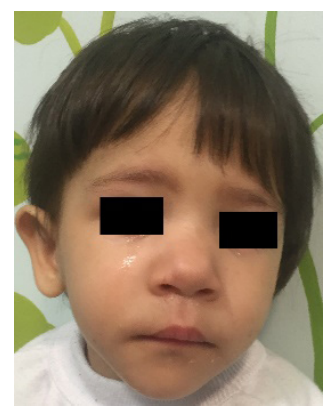

(a)

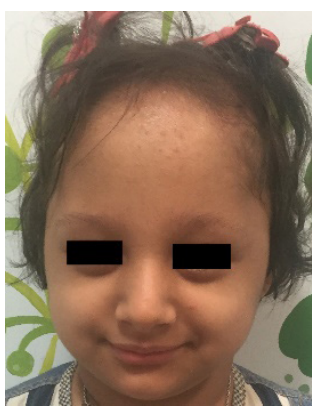

(e)

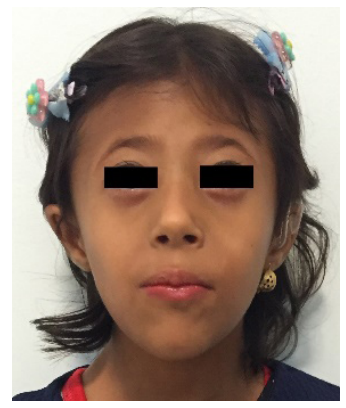

(b)

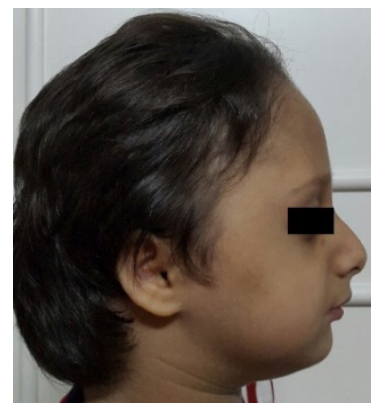

(f)

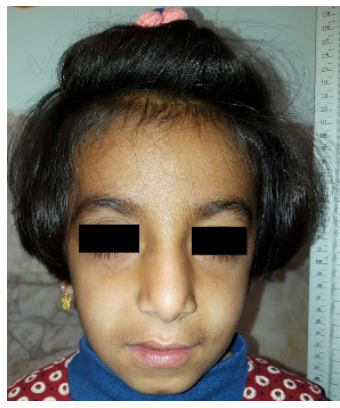

(c)

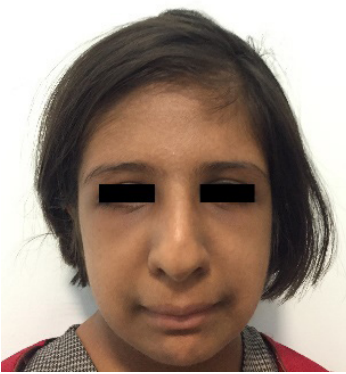

(g)

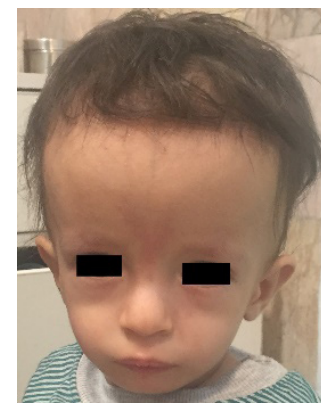

(d)

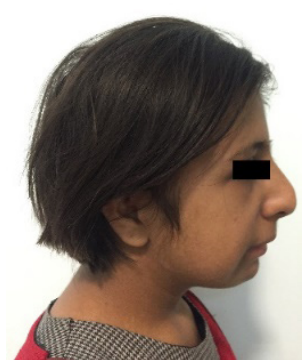

(h)

Figure 1. Clinical features of primordial dwarfism patients

Journal of Pediatrics Review

$\mathrm{a}$ and b. Seckel syndrome: Note microcephaly, narrow face and forehead, low-set ears, receding mandible and micrognathia; $c$, e, $\mathrm{f}, \mathrm{g}$ and $\mathrm{h}$ MOPD II: note microcephaly, long midface, prominent nose and eyes, thick eyebrows; d. Russell-Silver syndrome: Note large head (pseudo macrocephaly), triangular small face, prominent forehead, low-set ears, small jaw and thin upper lip 


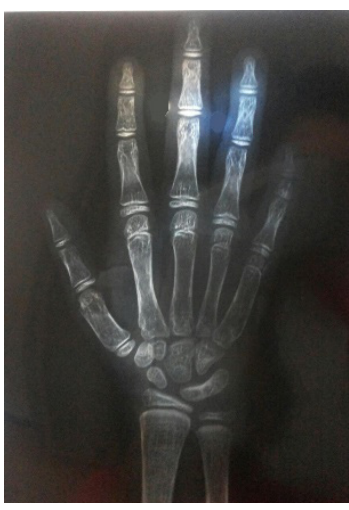

(a)

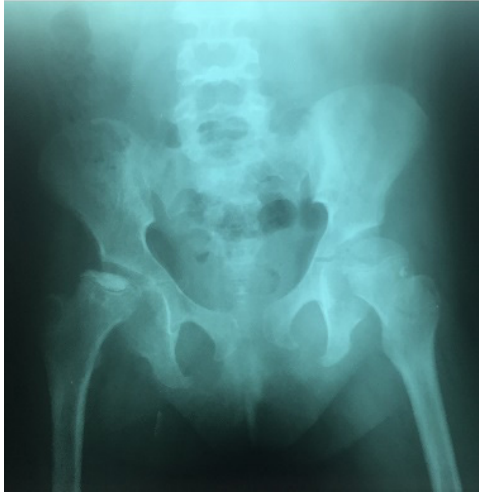

(b)

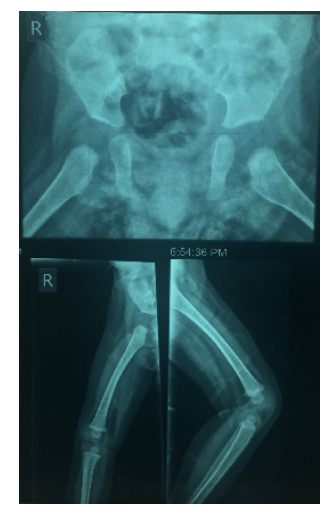

(c)

Figure 2. $X$-ray features of patients

Journal of Pediatrics Review

a. Hand X-ray of case 3: Note low bone density and fusion of two wrist bones; b. Pelvic X-ray of case 4: Note avascular necrosis of right femoral head (AVN); c. Pelvic X-ray of case 6: Note bone diastasis and lower limb asymmetry

present these cases by different methods. Some studies applied genetic and molecular analysis to confirm them. However, we could not use genetic assays, because they are not available everywhere in Iran. In detail, we presented 2 cases of Seckel syndrome, 3 cases of MOPD II and 2 cases of RSS. Parents agreed to present their children in our study. We studied 2 other cases whom their parents did not agree to report their children, thus we excluded them from the case presentation. Data summary of these 7 patients are listed in Table 2.

\section{Review of Literature}

We presented seven PD cases who were referred to our center with prenatal and postnatal growth delay, without any specific diseases. PD is an incurable group of disorders caused by various mechanisms, presenting with growth deficiency, facial dysmorphism, and brain anomalies, and results in very small body size, over life (8). Growth delay continues after birth and causes short stature. In addition, PD is a highly heterogeneous condition with different clinical features that can be classified into 5 major subtypes including Seckel syndrome, RSS, microcephalic osteodysplastic primordial dwarfism types I/III and II Meier-Gorlin syndrome (1).

Seckel Syndrome (SS) is characterized by severe microcephaly, large beaked nose, mild to moderate mental retardation and called it bird-headed dwarfism (5). Narrow face, dental anomalies (9-10), receding mandible, micrognathia, scoliosis, hip dislocation, delayed bone age, clinodactyly, low-set ear, sternal abnormalities and seizure are other signs and symptoms $(1,11)$. Dislocation of eye lens, hypopigmented macules and Morgagni hernia are reported in rare cases (1). MODP types I, III are rare dis- orders with autosomal recessive inheritance (12). The characteristic features are growth retardation, bone dysplasia, and central nervous anomalies (13), dry skin, thinning of scalp hair and eyebrows (1).

Patients with MODP I may have microcephaly, apnea, seizure, corpus callosum agenesis, short vertebra, bent femur and hip displacement. The signs of other subtypes of MOPD III are intrauterine growth retardation, clavicles and bone anomalies (1). Investigations found evidence that MOPD I and III are variations of one type and should be classified together, despite their radiologic and physical differences (13). Majewski Osteodysplastic Primordial Dwarfism type II (MOPD) is a distinct disorder. This rare autosomal recessive condition is estimated to be the most common type of PD (14).

Patients are characterize by IUGR, very low birth weight (less than $1500 \mathrm{~g}$ ) high-pitched voice (squeaky voice), prominent nose and eyes and narrow face, microdontia or missing teeth, skeletal anomalies such as delayed bone age, thin bones, coxavara, small iliac wings, flat acetabular angle, hip dislocation at birth, short first metacarpals, carpal bones fusion (6), borderline intellectual functioning or mild mental retardation, abnormal pigmentary changes $(1,14)$, problems in $80 \%$ of infants, and truncal obesity that may accelerate the puberty (15).

Another important feature of MOPD II is the early onset of cerebrovascular diseases such as cerebral aneurysm and occolusive arteriopathy (moyamoya disease) (16). Hematologic abnormalities such as anemia, leukocytosis and thrombocytosis may occur in affected patients $(1,15)$. The characteristic features of Russell-Sil- 
Table 2. Data summary of 7 cases with primordial dwarfism

\begin{tabular}{|c|c|c|c|c|c|c|}
\hline $\begin{array}{l}\text { No. of } \\
\text { Case }\end{array}$ & $\begin{array}{l}\text { Sex/ } \\
\text { Age }\end{array}$ & $\begin{array}{l}\text { Birth } \\
\text { Weight }\end{array}$ & Head Size & Facial Features & $\begin{array}{l}\text { Other Distinguishing } \\
\text { Features }\end{array}$ & $\begin{array}{l}\text { Clinical } \\
\text { Diagnosis }\end{array}$ \\
\hline 1 & $\begin{array}{l}\mathrm{F} / \\
1.5 \mathrm{y}\end{array}$ & $\begin{array}{l}1940 \mathrm{~g} \\
\text { (IUGR) }\end{array}$ & Microcephaly & $\begin{array}{l}\text { Narrow face, receding } \\
\text { mandible, pointed nose, } \\
\text { dental alterations, mi- } \\
\text { crophthalmia }\end{array}$ & Strabismus and cataracts & $\begin{array}{c}\text { Seckel } \\
\text { syndrome }\end{array}$ \\
\hline 2 & $\begin{array}{l}\text { F/ } \\
5 y\end{array}$ & $\begin{array}{l}870 \mathrm{~g} \\
\text { Preterm } \\
(35 \mathrm{wk})\end{array}$ & Microcephaly & $\begin{array}{c}\text { Narrow face, receding } \\
\text { mandible, large eyes, low- } \\
\text { set ears, dental anomalies, } \\
\text { odontia }\end{array}$ & $\begin{array}{l}\text { Bilateral sensory neural hearing } \\
\text { loss, flexion contracture of } \\
\text { fingers }\end{array}$ & $\begin{array}{l}\text { Seckel syn- } \\
\text { drome }\end{array}$ \\
\hline 3 & $\begin{array}{l}\text { F/ } \\
8 y\end{array}$ & $\begin{array}{l}1900 \mathrm{~g} \\
\text { (IUGR) }\end{array}$ & Microcephaly & $\begin{array}{c}\text { Narrow and long midface } \\
\text { prominent nose, large } \\
\text { eyes, thick eyebrows, small } \\
\text { ears }\end{array}$ & $\begin{array}{l}\text { High-pitched voice, feeding } \\
\text { problem }\end{array}$ & MOPDII \\
\hline 4 & $\begin{array}{l}\text { F/ } \\
8 y\end{array}$ & $\begin{array}{l}900 \mathrm{~g} \\
(28 \mathrm{wk})\end{array}$ & Microcephaly & $\begin{array}{l}\text { Prominent nose and eyes, } \\
\text { hair thinning of scalp and } \\
\text { eyebrows, microdontia and } \\
\text { missing teeth and/or poor } \\
\text { teeth roots }\end{array}$ & $\begin{array}{l}\text { Avascular necrosis of right } \\
\text { femoral head ,anemia, throm- } \\
\text { bocytopenia, radial deviation of } \\
\text { 4th and 5th hand fingers }\end{array}$ & MOPD II \\
\hline 5 & $\begin{array}{l}\mathrm{F} / \\
12 \mathrm{y}\end{array}$ & $\begin{array}{l}1680 \mathrm{~g} \\
\text { (IUGR) }\end{array}$ & Microcephaly & $\begin{array}{l}\text { Microcephaly, thin hair, } \\
\text { widely spaced primary } \\
\text { teeth, microdontia, promi- } \\
\text { nent nose and eyes }\end{array}$ & $\begin{array}{c}\text { Delayed mental development, } \\
\text { truncal obesity, precocious } \\
\text { puberty }\end{array}$ & MOPD II \\
\hline 6 & $\begin{array}{l}\mathrm{M} / \\
1.5 \mathrm{y}\end{array}$ & $\begin{array}{l}1580 \mathrm{~g} \\
\text { (IUGR) }\end{array}$ & Normal & $\begin{array}{l}\text { Triangular small face, } \\
\text { small jaw, thin upper lip, } \\
\text { prominent forehead, low } \\
\text { set ear, }\end{array}$ & $\begin{array}{l}\text { Bilateral mild hearing loss, } \\
\text { lower limb asymmetry and } \\
\text { diastasis in symphysis pubis in } \\
\text { x-ray imaging }\end{array}$ & $\begin{array}{l}\text { Russell-Silver } \\
\text { syndrome }\end{array}$ \\
\hline 7 & $\mathrm{M} / 3.5 \mathrm{y}$ & $\begin{array}{l}680 \mathrm{~g} \\
(29 w \mathrm{w})\end{array}$ & $\begin{array}{c}25 \mathrm{~cm} \\
\text { Normal for } \\
\text { gestational age }\end{array}$ & $\begin{array}{l}\text { Triangular face, small chin, } \\
\text { bossed forehead, low-set } \\
\text { ears, thin upper lip. }\end{array}$ & $\begin{array}{l}\text { Hypothyroidism, bilateral renal } \\
\text { stones }\end{array}$ & $\begin{array}{l}\text { Russell-Silver } \\
\text { syndrome }\end{array}$ \\
\hline
\end{tabular}

ver syndrome are low birth weight, short stature, body asymmetry $(17,18)$, and normal head size (1). Other diagnostic features are small triangular face, micrognathia, dental anomalies, prominent forehead that causes pseudo microcephaly (19). Feeding difficulties such as malnutrition, gastrointestinal reflux and vomiting are frequent signs in infants and children with RSS (20).

Meier-Gorlin syndrome (ear-patella-short stature syndrome) is another type of PD that was first described in 1959, in which Meier et al. described a case with micrognathia, microtia, absent patellae, and cryptorchidism (7). The major diagnostic criteria of this syndrome include bilateral small ears, aplasia or hypoplasia of patellae, and short stature with normal mentality (21). Other clinical features include microcephaly, lower limb arthrogryposis, cryptorchidism, hypogonadism, deafness, curved clavicle and deformed ribs $(1,19)$.

We reported 7 patients with severe progressing growth deficiency from birth. The diagnosis was made based on severe growth retardation, specific clinical findings and ruling out other similar situations. Laboratory tests were assessed in all cases to differentiate apparently similar disorders with primordial dwarfism, such as Fanconi anemia, Bloom syndrome, 3M syndrome, etc. $(1,18)$.
In laboratory examination, one of the MOPD II cases showed anemia and thrombocytosis after 2 years fallow up (case 4). However, other tests were normal in all patients. Chromosomal studies were normal in all cases.

Radiologic studies showed delayed bone age in all patients. Other findings included thin bones and Avascular Necrosis (AVN) of right head of femur (AVN type 3 ) in our case 4 . AVN and hip instability may occur in underlying disorders or growth hormone therapy in PD patients. Another finding was carpal bones fusion, shown in Figure 2. Brain imaging showed no evidence for cerebrovascular diseases. Cerebrovascular diseases occur in 32\% of MOPD II patients. Occlusive arteriopathy can be clinically silent and occur in younger individuals (16). Different clinical findings in PD patients can be due to mutations of various genes (3). Also, chromosomal studies have reported specific changes in different subtypes of PD (1). Findings of molecular, genetic and chromosomal changes can be useful to differentiate PD subtypes from each other.

This may help in screening and prenatal diagnosis of families in future. Management of PD patients is a problem when the objective is improvement of patient's final stature. There are no effective treatment available for 
some aspects of primordial dwarfism. Growth studies revealed that human Gowth Hormone (GH) therapy can improve final height and result in a positive growth response (22). Many investigations estimated the effect of $\mathrm{GH}$ therapy on different types of PD. Most of these studies reported no improvement in final stature, following $\mathrm{GH}$ therapy in MOPD type II patients. There is no study on MOPD types I/III (1). Birbaek et al. demonstrated improvement in growth rate after GH therapy in Seckel cases (1); however, it is not approved by other studies. Also, Munnik et al. reported an increase in growth rate following GH therapy in Meire-Gorlin syndrome (1).

RSS is an indication for GH therapy under the SGA registered license in the USA and European Medicine Agency. Clinical trials approved GH therapy for patients with RSS (23). We have applied GH treatment in 2 of our cases with RSS since 4 months ago. Both of them responded to GH therapy with an increase of 3-4 cm in height (length for head $z$ score improved from -5.7 to -4.8 in case 6 and from -5 to -4.2 in case of 7), that showed benefit in our patients. Studies revealed that GH treatment can be effective for some subtypes of PD. However further studies are required to appoint the indications of $\mathrm{GH}$ therapy for primordial dwarfism patients.

This review and case presentation study aimed to present an overview of clinical features of PD patients. However, we could not confirm these findings with genetic analysis. Therefore, further studies are required to reveal molecular and chromosomal alterations, in order to discuss overall characteristics of this disorder.

\section{Ethical Considerations}

\section{Compliance with ethical guidelines}

There is no ethical principle to be considered doing this research.

\section{Funding}

This research did not receive any specific grant from funding agencies in the public, commercial, or not-forprofit sectors.

\section{Authors contributions}

All authors have read and approved the manuscript.

\section{Conflict of interest}

The authors declare no conflict of interest.

\section{References}

1. Khaetarpal P, Das Kh, Panigrahi I, Munshi A. Primoral dwarfism: Overview of clinical and genetic aspects. Molecular Genetics and Genomics. 2016; 291(1):1-15. [DOI:10.1007/ s00438-015-1110-y] [PMID])

2. Codd PJ, Scott RM, Smith ER. Seckel syndrome and moyamoya: Case report. Journal of Neurosurgery: Pediatrics. 2009; 3(4):320-4. [DOI:10.3171/2008.12.PEDS08205] [PMID]

3. Klingsein A, Jackson AP. Mechanisms and pathways of growth failure in primordial dwarfism. Genes Development. 2011; 25(19):2011-24. [DOI:10.1101/gad.169037] [PMID] [PMCID]

4. Filonava L, Torres AG, de Pouplana LR. A novel cause for primordial dwarfism revealed: Defective tRNA modification. Genome Biology. 2015; 16(1):216.

5. Vardhan BH, Muthu MS, Saraswathi K, Koteeswaran D. Birdheaded dwarf of Seckel. Journal of Indian Society of Pedodontics and Preventive Dentistry. 2007; 25(5):8-9.

6. Seckel HP, editor. Bird-headed dwarfs: Studies in developmental anthropology including human proportions. Pediatrics. 1961; 27(3):426-9.

7. Seymen F, Tuna b, Kayserili H. Seckel syndrome: Report accuses. Journal of Clinical Pediatric Dentistry. 2002; 26(3):305-9.

8. Kjær I, Hansen N, Becktor KB, Birkebaek N, Balslev T. Craniofacial morphology, dentition, and skeletal maturity in four siblings with seckel syndrome. The Cleft Palate-Craniofacial Journal. 2001; 38(6):645-51. [DOI:10.1597/15451569_2001_038_0645_cmdasm_2.0.co_2]

9. Mokrani Benhelli H, Gaillard L, Biasutto P, Guen T, Touzot $\mathrm{F}$, Vasquez N, et al. Primary microcephaly, impaired DNA replication and genomic instability caused by compound heterozygous ATR mutations. Human Mutation. 2013; 34(2):374-84. [DOI:10.1002/humu.22245] [PMID]

10. Majweski F, Goecke T. Studies of microcephalic primordial dwarfism I: Approach to a delineation of the seckle syndrome. American Journal of Medical Genetics. 1982; 12(1):7-21. [DOI:10.1002/ajmg.1320120103] [PMID]

11. Meinecke P, Passarge E. Microcephalic osteodysplastic primordial dwarfism type I/II in sibs. Journal of Medical Genetics. 1991; 28(11):795-800. [DOI:10.1136/jmg.28.11.795]

12. Melinda J, Pierce RP, Morse RP. The neurologic findings in Taybi- Linder syndrome (MOPD I/II): Case report and review of the literature. American Journal of Medical genetics. 2012; 158(3):606-10. [DOI:10.1002/ajmg.a.33958] [PMID]

13. Rauch A. The shortest of the short: Pericentrin mutations and beyond. Best Practice \& Research Clinical Endocrinology \& Metabolism. 2011; 25(1):125-30. [DOI:10.1016/j. beem.2010.10.015] [PMID] 
14. Hall JG, Flora C, Scott Cl, Pauli RM, Tanaka KI. Majweski osteodysplastic primordial dwarfism type II (MOPD II): Natural history and clinical findings. American Journal of Medical Genetics. 2004; 130(1):55-72. [DOI:10.1002/ ajmg.a.30203] [PMID]

15. Luck D, Robertson F, Ganesan V. Screening for cerebrovascular disease in Microcephalic Osteodyspalstic Primordial Dwarfism type II (MOPD II): An evidence- based proposal. Pediatric Neurology. 2013; 48(4):294-8. [DOI:10.1016/j. pediatrneurol.2012.12.010] [PMID]

16. Kent T, Yamaguchi Jr, Jennifer B, Salam MA, Karen S, Myung MD, et al. Spinal deformity in Russell-silver syndrome. Spinal Deformity. 2015; 3(1):95-7. [DOI:10.1016/j. jspd.2014.06.003] [PMID]

17. Rao VB, Lily K, Seema K, Ghosh K, Dipika M. Paternal reciprocal translocation $\mathrm{t}(11 ; 16)(\mathrm{p} 13 ; \mathrm{q} 24.3)$ in a Silver-Russel syndrome patient. Annales de Génétique. 2003; 46(4):4758. [DOI:10.1016/S0003-3995(03)00028-5]

18. Clayton PE, Hanson D, Magee L, Murray PG, Saunders E, Abu Amero SN, et al. Exploring the spectrum of 3-M syndrome, a primordial short stature disorder of disrupted ubiquitination. Clinical Endocrinology. 2012; 77(3):335-42. [DOI:10.1111/j.1365-2265.2012.04428.x]

19. Marsaud C, Rossingnol S, Tounian P, Netchine I, Dubern B. Prevalence and management of gastro intestinal manifestation in silver- Russell syndrome. Archives of Disease in Childhood. 2015; 100(4):353-8. [DOI:10.1136/archdiss child-2013-305864] [PMID]

20. Sonja A, De Munnik, Hoesloot E, Roukema J, Schoots J, Kneors N, et al. Meier- Gorlin syndrome. Orphanet Journal of Rare Diseases. 2015; 10:114. [DOI:10.1186/s13023-0150322-x] [PMID] [PMCID]

21. Shawky RM, Gamal R. Meier-Gorlin syndrome: An additional Egyptian patient with gastroesophageal reflux, hydronephrosis, renal stones and hypoplastic labia majora and minora with clitromegaly. Egyptian Journal of Medical Human Genetics. 2016; 17(4):397-400.

22. Ranke MB, Lindberg A, Mullis PE, Geffner ME, Tanaka T, Cutfield WS, et al. Towards optimal treatment with growth hormone in short children and adolescents: Evidence and theses. Hormone Research in Pædiatrics. 2013; 79(2):5167. [DOI:10.1159/000347121] [PMID]

23. Wakeling EL, Brioude F, Lokulo Sodipe O, O'connell SM, Salem J, Bliek J, et al. Diagnosis and management of SilverRussell syndrome: First international consensus statement. Nature Reviews Endocrinology. 2017; 13(2):105. 